\title{
How relevant is the evidence-based process to orthodontics
}

\section{Bill Shaw}

\section{Co-ordinating Editor of the Cochrane Oral Health Group}

There is now a vast amount of empirical research, some of it quite old, to show that non-controlled studies are much more likely to reach a distorted or inflated view of effectiveness.

Lysle Johnston's observations, as ever, give plenty of food for thought, and as Lysle (see this issue) has done more than anyone in North America to challenge the irrational dogma and of much of the American orthodontic industry, he knows whereof he speaks.

He rightly points out that some questions are more important than others and that our energies should be conserved for the more important ones. And I agree that for a limited number of questions we must respect alternative research methodologies to the randomised trial. One would certainly like to see utility analysis used much more for comparisons of dissimilar interventions in dentistry, such as orthognathic surgery versus orthodontics.

But why is the randomised clinical trial, in Lysle's words, so 'exalted'? Is this really just intellectual snobbery? As someone who has done as much as anyone to muddy the waters of clinical science through uncontrolled retrospective studies, some of them worryingly large, I might be tempted to agree. However, by dint of my involvement in the Cochrane Collaboration, my worse fears of the influence of bias in research have sadly been confirmed. There is now a vast amount of empirical research, some of it quite old, to show that non-controlled studies are much more likely to reach a distorted or inflated view of effectiveness. For instance, one review of 52 published uncontrolled trials in psychiatry found that $85 \%$ of them reported therapeutic success, whereas, in 20 published trials with a control group, only 25\% reported therapeutic success. ${ }^{1}$ Similarly, a review of 53 studies of portacavel shunt operation for portal hypertension found that, of 32 uncontrolled studies, $75 \%$ were markedly enthusiastic, whereas 6 controlled trials found little or no support. ${ }^{2}$ And, in one comparison of a series of historical control studies, the new treatment was found to be superior in $79 \%$ of studies. With randomisation, the figure fell to $20 \%{ }^{3}$ The pervasive effect of bias can even distort randomised trials where the randomisation arrangements are not fully concealed. ${ }^{4}$

Undoubtedly uncontrolled orthodontic research is just as flawed, but is it realistic to replace it with randomised trials? The answer, I believe, is undoubtedly 'yes', though it may be more easy in some places than others. In the US, funds were provided in the mid-nineties by the National Institute for Dental Research for studies of the treatment of Class II malocclusion and results have begun to emerge from three randomised trials initiated at academic centres. ${ }^{5-7}$ These studies will probably be criticised, however, as they may not represent the real world. But orthodontics in the US is a commodity largely delivered by small businesses, often in mutual competition, which makes it difficult to achieve the co-operation necessary to generate adequate samples in everyday practice. Sadly it is hard to see this situation change unless the inadequacy of current knowledge is acknowledged by its practitioners and explained to its consumers. On the other hand, a large proportion of orthodontic care, mainly for complex malocclusion, is provided in the UK by a network of NHS consultant units. Twelve of those units are currently cooperating in two concurrent randomised trials of Class II treatment led by Kevin O'Brien and with full ethical consent 400 patients have been enrolled in treatment, (at a fraction of the cost of the US trials). One can easily envisage similar networks of British general dental practitioners, perhaps under the auspices of the Faculties of Dental Surgery at the Royal Colleges, collaborating on randomised trials to address a host of important tasks undertaken each day in dentistry. Again the crucial starting point for such initiatives will be the forthright acknowledgement that our current knowledge just isn't reliable.

If I disagree with Lysle Johnston, it is in our differing level of optimism for the range and complexity of trials that we will be able to do, with full ethical consent of patients. In a current multicentre trial of primary cleft lip and palate surgery in the UK and Scandinavia, coordinated by Gunvor Semb, $96 \%$ of parents have elected to have their children participate. And we can 
take heart from other disciplines that have overcome the challenges involved in mounting trials of surgery versus conservative treatment, or treatment versus no treatment for a range of conditions. ${ }^{8-14}$

Jayne Harrison's systematic review of crossbite was inevitably constrained by the desultory quality of research that typifies orthodontics today. But she is young enough to be confident that her hard won skills will come in useful for future systematic reviews of better orthodontic research. I wish the same could be said for Lysle and me.

1. Foulds GA. Clinical research in psychiatry. J Ment Sci 1958;104:259-265.

2. Grace ND, Muench $\mathrm{H}$, Chalmers TC. The present status of portal hypertension in cirrhosis. Gastroenterology 1966; 50:684691.

3. Sacks $H$, Chalmers TC, Smith $H$.
Randomised versus historical controls for clinical trials. Am J Med 1982;72:233-240.

4. Kunz R, Oxman AD. The unpredictability paradox: review of empirical comparisons of randomised and non-randomised clinical trials. BMJ 1998; 317:1185-1190.

5. Keeling et al. Anteroposterior skeletal and dental changes after early Class II treatment with bionators and headgear. Am J Orthod Dentofacial Orthop 1998; 113:40-50.

6. Ghafari J et al. Headgear versus function regulator in the early treatment of Class II, Division 1 malocclusion: A randomized clinical trial. Am J Orthod Dentofacial Orthop 1998;13:51-61.

7. Tulloch JFC et al. Benefit of early Class II treatment: Progress report of a two-phase randomized clinical trial. Am J Orthod Dentofacial Orthop 1998;113:62-72.

8. Arrigada R, Le MG, Rochard F, Contesso G. Conservative treatment versus mastectomy in early breast cancer: patterns of failure with 15 year follow-up data. Institut Gustave-Roussy Breast Cancer Group. J Clin Oncol 1996;14:1558-1564.

9. Frazee RC, Roberts JW, Symmonds RE et al. A prospective randomised trial comparing open versus laparoscopic appendectomy. Ann Surg 1994; 219:725731.

10. Lawrence K, McWhinnie D, Goodwin A et al. Randomised controlled trial of laparoscopic versus open repair of inguinal hernia: early results. BMJ 1995;311:981985.

11. Majeed AW, Troy G, Nicholl JP et al. Randomised, prospective, single blind comparison of laparoscopic versus small incision cholecystectomy. Lancet 1996;347:989-984.

12. Morris AD, Morris RD, Wilson JF et al. Breast-conserving therapy vs. mastectomy in early-stage breast cancer: a metaanalysis of 10-year survival. Cancer Journal from Scientific American 1997;3:6-12.

13. Van der Linden $W$ and Larsson K. Plate fixation versus Conservative treatment of tibial shaft Fractures. J Bone Joint Surg 1979;61A:873-878.

14. Worsaae N, Thorn JJ. Surgical versus nonsurgical treatment of unilateral dislocated low subcondylar fractures: a clinical study of 52 cases. J Oral Maxillofac Surg 1994; 52:353-360. 